\title{
Review of Research in Education
}

http://rre.aera.net

Chapter 1: Individual and Social Aspects of Learning

Gavriel Salomon and David N. Perkins

REVIEW OF RESEARCH IN EDUCATION 1998; 23; 1

DOI: 10.3102/0091732X023001001

The online version of this article can be found at:

http://rre.sagepub.com

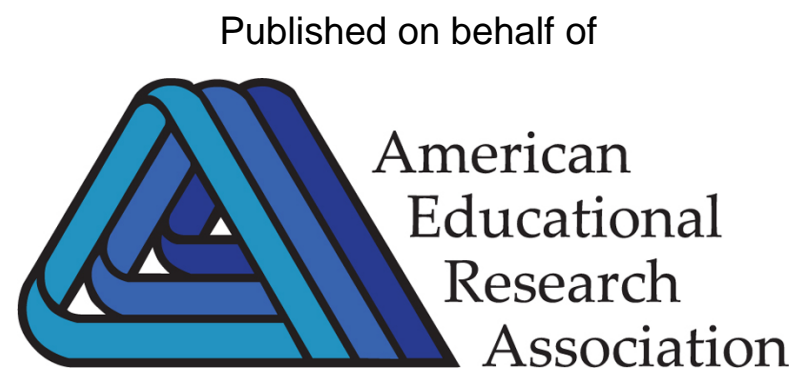

http://www.aera.net

By

(9) SAGE

http://www.sagepublications.com

Additional services and information for Review of Research in Education can be found at:

Email Alerts: http://rre.aera.net/cgi/alerts

Subscriptions: http://rre.aera.net/subscriptions

Reprints: http://www.aera.net/reprints

Permissions: http://www.aera.net/permissions 


\title{
Chapter 1
}

\section{Individual and Social Aspects of Learning}

\author{
GAVRIEL SALOMON \\ Haifa University \\ DAVID N. PERKINS \\ Harvard Graduate School of Education
}

Social learning is in the air. Daily observations and experiences as well as recent scholarly traditions suggest that a certain amount of learning takes place beyond the confines of the individual mind. Learning appears to involve social aspects. Scenarios ranging from a group of children collaboratively trying to solve the question of how to construct a kite to a university professor writing a research paper with a colleague advance the case for a social side to learning.

But impressions do not make social learning an obvious category. Are there any theoretical and empirical grounds to justify social learning as a distinctive phenomenon? Is there anything qualitatively different in this kind of learning to distinguish it from the familiar individual conception of learning? Can one make the case that social learning is more than an epiphenomenon or individual learning multiplied, that the social aspects of learning are anything more than the kind of secondary help a learner might get from audiovisual displays, bookmarks, and road signs?

If we can raise the question of whether social learning is a valid and viable phenomenon, the opposite question might equally well be raised: Is it not possible that solo learning is simply a figment of the traditional laboratory-based psychology, on the one hand, and of a socially shared respect for the individual qua individual, on the other? The idea of social learning is not really new, having been an important part of early developments of the science of psychology ("folkspsychology," as formulated, for example, by Munsterberg [1914, cited in Cole \& Engestrom, 1993]). This branch of psychology fell into neglect because of its Gestalt-like nature and thus its alleged lack of rigor, its central phenomena left to anthropology and sociology to handle. It was distinguished from the more rigorous laboratory-based, experimentally oriented, and far more prestigious psychology of Ebbinghouse. Social learning has thus continued to be largely ignored by psychologists over the years, relegated at best to the study of background context, not really on a par with the learning of the individual (Gardner, 1985).

This relative neglect now appears to have been corrected. With the growing interest in Vygotsky's theory, retrospective examinations of the role of social inter-

We wish to thank the reviewers of this chapter, Stellan Ohlsson and Orlando Lourenço, for their valuable comments and suggestions. Some of the ideas discussed herein were developed as part of a collaboration involving David N. Perkins and the Universidad Jorge Tadeo Lozano, Santa Fe de Bogota, Colombia, on the theme of organizational learning. 
actions in Piaget's works (DeVries, 1997; Lourenço \& Machado, 1996), Bandura's (1989) reformulation of the individual in reciprocal relations with the social environment, the conception of learning as a constructive (and, hence, socially and culturally situated) process (e.g., Lave \& Wenger, 1991), and newly designed empirical work, the study of individuals' learning has come to be embedded in social and cultural contexts and interactions. A focus on the individual learning in social and cultural solitude is increasingly being seen as conceptually unsatisfying and ecologically deficient. As Bronfenbrenner (1977) has pointed out, "In ecological research, the principal main effects are likely to be interactions" (p. 518), and these interactions occur, to a large extent, among an individual, his or her social surroundings, and the artifacts culture provides.

Two conceptions of learning seem to be involved here, each with its own metaphor. On one hand, we have the conception of the individual learner, emphasizing the acquisition of knowledge and cognitive skill as transferable commodities (e.g., Anderson, Reder, \& Simon, 1996). On the other hand, we have the sociocultural conception of learning as a collective participatory process of active knowledge construction emphasizing context, interaction, and situatedness (e.g., Cole \& Engestrom, 1993). Thus, one can speak of the "cognitive, acquisition-oriented" conception of individual learning versus the "situative, participatory" conception (e.g., Greeno, 1997; Sfard, in press).

It is fruitful to view these conceptions as two levels of analysis, each of which sometimes neglects the other. One can make an analogy with two perspectives on the spread of a flu: cell biology and epidemiology (Ohlsson, S., personal communication, June 23, 1997; Sperber, 1984). Clearly, the two complement each other: Subverted cellular mechanisms figure in the invasion of individual cells by viruses, but the viruses have to arrive at individual cells to infect them. Although each process can be understood in its own right, understanding the interplay yields a richer and conceptually more satisfying picture.

Something similar might be said of learning: It takes place in individuals' minds, and, as we elaborate later, it takes place as a social, participatory process, offering two distinctively different perspectives on learning. While each of these perspectives is often treated independently of the other, our aim here is to examine their interrelationships, not as two separate logical categories but as two perspectives on the phenomena of learning. Thus, while children often practice arithmetic or climbing trees alone, "individual" learning is rarely truly individual; it almost always entails some social mediation, even if not immediately apparent. Likewise, the learning of social entities (e.g., teams) entails some learning on the part of participating individuals. It is such variations in kind and balance that we mean to examine.

Specifically, our goals in this chapter are as follows. First, we want to clarify the distinctive meanings of the notion of social learning vis-à-vis individual learning. Second, against that backdrop, we want to examine the possibility that social learning, in its various senses, is a distinctive and important way of looking at learning. Finally, with both the "acquisition" and the "participation" metaphors in view, we want to suggest ways in which individual and social aspects of learning interrelate and interact in synergistic ways.

\section{A MAP OF THE TERRITORY}

Teasing the varied meanings of social learning apart and illuminating their nature is a daunting endeavor. To make the mission easier, we adopt a loose but 
unifying information-processing perspective on learning within which different views of learning can be described, compared, and contrasted. As used here, the idea of information processing includes no biasing presumptions about where those processes lie or what entity they serve (e.g., Hutchins, 1996; Perkins, 1993). The information processes in question might occur within the mind of an individual or within complex webs of social interaction. The entity learning might be an individual or a social entity such as a team, a corporation, a loose group of individuals, or even a society. In any case, information is being processed, and learning and forgetting occur in the sense that lasting changes resulting from the processingwhether "in" the individual or "in" a social entity-can be identified.

From the standpoint of information processing, learning for individuals or collectives is a considerable challenge. The learning entity in question, whether a person trying to skate better or a loose society of individuals trying to get along with one another, must be able to construct a repertoire of new representations or behaviors based on prior experience. It must have the opportunity to test and select among alternative representations or behaviors, or refine one or combine them. It will need feedback of some sort, from internal or external sources, about how well an alternative fares. It can benefit greatly from information sources-anything from a text to the incidental or deliberate modeling provided by another wiser agent performing the activity in question - as well as guidance through self-regulation or provided by others. To learn, it will need to face an approachable but manageable level of challenge, not too hard to cope with but not so easy as to yield completely to the existing repertoire. The learning entity will also need conditions that sustain motivation and energy. And so on.

In other words, learning by any entity in any setting has what might be called critical conditions. Such conditions figure not only in the logical story of how learning can come about but in the practical story of ensuring that it does come about. Often learning fails not for subtle reasons, such as the learner missing the point, but for gross reasons, such as the lack of a source to provide an important point.

With such general challenges in mind, it is useful to speak of a learning system as an information-processing system aimed at facilitating these critical conditions for the learning entity in question. Thus, simple trial-and-error learning of an individual organism through reinforcement is one kind of learning system, with certain ways of dealing with such critical conditions as generating alternatives (by accidentally varying behaviors) and selecting alternatives (through reinforcement). Learning that involves deeper understanding aided by peers in a collaborative setting is yet another kind of learning system, in which alternatives are provided by different team members and the selection of the best one is a matter of detailed deliberations and agreements.

The ideas of critical conditions for learning, on the one hand, and learning systems designed to facilitate those conditions, on the other, provide a backdrop for addressing the question posed earlier: What are the distinctive meanings of social learning? We distinguish six meanings for the sake of conceptual clarity. In later sections, we elaborate further on the first four as more concerned with the dynamics of learning.

1. Active social mediation of individual learning. In human society, one of the 
most fundamentally social forms of learning is that in which a person or a team helps an individual to learn. A teacher teaches reading, writing, and arithmetic; parents correct a child's ungrammatical utterances or misuse of words on the fly; a master takes on apprentices and guides their development; children work together to master algebra problems, each learning from the other. In such cases, the facilitating agent and the primary learner form a joint learning system, the former helping the latter to achieve critical conditions of learning. For instance, the agent may provide information in the form of instruction or demonstrations, informative feedback about what is right or wrong and what to do instead, approachable but challenging tasks, encouragement, scaffolding of the learner's performance as it unfolds with tips and hints, and so on.

The exact forms taken by such learning systems vary, of course: A skilled individual tutor can tune the learning system much more finely to a particular individual than a classroom teacher can to a room full of individuals (Lepper, Aspinwall, Mumme, \& Chabay, 1990; Lepper, Drake, \& O’Donnell-Johnson, 1997). A team studying together can elaborate on a member's attempts to solve something the individual could not do on his or her own (Damon, 1984; Slavin, 1994). But such differences aside, the broad idea is the same: to create a better learning system for the primary learner by bringing in a facilitating social agent to help meet the critical conditions of learning.

Loosely speaking, socially mediated individual learning might be considered the same as instruction, and the point no more than that instruction inevitably involves a certain amount of social mediation. But far more is at stake than this. Instruction, in its prototypical forms (involving lecturing or question-and-answer sessions), may be considered a special case—albeit not a very interesting one-of social learning. However, as a learning system, it often does not meet the critical conditions of learning very well. And, when regular instruction is, in fact, effective, the processes involved may not be very socially mediated (as, for instance, when skilled students learn effectively from lectures because of their own autoregulation skills, but rarely from each other).

2. Social mediation as participatory knowledge construction. In the version of active social mediation sketched so far, there is a clear distinction between individuals and the learning products they carry away as their transferable cognitive possession, on the one hand, and the social agents facilitating that learning, on the other. But there is a second version of social mediation that deserves recognition: the sociocultural version, which sees learning less as the socially facilitated acquisition of knowledge and skill and more as a matter of participation in a social process of knowledge construction (e.g., Cole, 1995; Greeno, 1997). Although the illustrative phenomena are the same-individual tutoring, team problem solving, collaborative and cooperative learning, and so on - the way they are understood in this second version of active social mediation is very different. Social mediation of learning and the individual involved are seen as an integrated and highly situated system in which the interaction serves as the socially shared vehicles of thought. Accordingly, the learning products of this system, jointly constructed as they are, are distributed over the entire social system rather than possessed by the participating individual. 
3. Social mediation by cultural scaffolding. Even when a learner does not receive direct help from another agent actively adjusting to the learner's needs-the first case of social mediation mentioned earlier-the learner may enter into some kind of intellectual partnership or at least be greatly helped by cultural artifacts in the form of tools and information sources. Such artifacts can range from books and videotapes that tacitly embody shared cultural understandings (Perkins, 1986) to statistical tools and socially shared symbol systems embodying, for instance, a "language of thinking" that includes such finely distinguished terms as hypothesis, conjecture, theory, and guess (e.g., Gigerenzer, 1991; Tishman \& Perkins, 1997). Artifacts are themselves culturally and historically situated, carrying the wisdom and hidden assumptions that went into their design. Thus, they form a learning system with the learner, reorganizing action and determining what can be carried out (along with when, where, in what form, and for what purpose) (e.g., Cole, 1995).

4. The social entity as a learning system. Another very different meaning of social learning occurs when people speak of learning involving teams, organizations, cultures, or other collectives (e.g., Argyris, 1993; Argyris \& Schon, 1996; Huber, 1989; Levitt \& March, 1988; Senge, 1990). Here it is not necessarily the case that one agent is helping another to learn. Rather, the focus falls on a collective agency that, as a collective, acquires more knowledge, understanding, or skill, or a different climate or culture. A sports team attains patterns of coordination among the individuals that might be quite useless for any of the team members functioning alone. A business organization develops internal procedures, based on commonly held tacit assumptions, that meet customer demands more efficiently and more quickly. In such cases, the agreements need not be stated, and the procedures are not executed (and perhaps not even overseen) by any one individual, but they advance the performance of the organization. In summary, the group constitutes a collective learning system, a system that will function better or worse as a learner depending on how well its structures address critical conditions of learning.

5. Learning to be a social learner. Still another sense of social learning concerns a special case of learning: learning to learn. Contemporary cognitive science recognizes that learning to learn is a fundamental aspect of learning (e.g., Chipman, Segal, \& Glaser, 1985; O'Neil \& Spielberger, 1979; Perkins, 1995; Pressley \& Brainerd, 1985; Segal, Chipman, \& Glaser, 1985). Youngsters acquire knowledge, understanding, and skill not only in particular areas (e.g., language use, soccer, or algebra) but about learning itself. For instance, the field of "metamemory" concerns children's developing understanding of their own memories and how to manage memory (Pressley \& Brainerd, 1985). Of course, all of this applies to the learner functioning individually. However, an important dimension of learning to learn involves learning to learn in ways that participate in and capitalize on the social milieu. One simple aspect is learning when and how to ask questions or to ask for help. Another is learning how to enter into reciprocal learning relationships ('I'll help you with this if you help me with that, or we will both help one another with this particularly difficult idea"). Here, the individual learner's learning system 
extends its capacity to deal with the critical conditions of learning by acquiring new ways to capitalize on the social surroundings.

6. Learning social content. The foregoing categories all concern social factors in the service of learning. Attention to certain of these is the principal purpose of this chapter. Solely for the sake of logical completeness, another possible meaning of social learning needs to be acknowledged: the learning of social content. Social content includes such matters as how to get along with others, how to maintain reasonable assertiveness, how to collaborate in reaching decisions and taking collective actions, and so on. This sense of social learning is quite different from those considered previously. To speak of the learning of social content is not to introduce any new way of understanding learning systems, as the other perspectives have done. Here the learning system would be one of those already discussed, operating on social content.

With six meanings of social learning in view, the first four provide the natural focus for development. All four deal with what might be called the dynamics of learning, in contrast with the last two, which deal more with what is learned. The first, social mediation by an active agent (social mediation for short), reflects a range of major figures and lines of inquiry in such areas as cognitive development; tutoring; peer tutoring; collaborative, cooperative, and reciprocal learning; and more. The second involves a major stream of contemporary thinking that emphasizes participatory learning and "distributed, situated cognition." The third deals with the mediating role that tools and cultural artifacts, embodying accumulated social wisdom, play in the process of learning. And the fourth reflects a tide of interest in team and organizational learning sustained by practical interests in the worlds of business, government, and sports and by the inquiries of psychologists, sociologists, and anthropologists into the workings of collectives of various kinds and sizes.

\section{FOUR PERSPECTIVES}

With these four perspectives and the ideas of critical conditions and learning systems at hand to organize the analysis, we take a close look at the social mediation of learning in the next section, followed by discussions of participatory learning, mediation through cultural tools, and, finally, the learning of collective entities.

\section{The Social Mediation of Individual Learning}

The simplest and most familiar modes of social mediation are configurations of one to one (tutor, parent, or teacher to learner), one to many (teacher to a group), and many to one (a pair, trio, or other group of collaborative learners with the learner as a participant). In all of these cases, the interactions between the learner and the "other(s)" are expected, and often found, to enhance the individual's learning. Two distinguishable entities are involved in the learning system: the learner and the "other," entities sometimes in complementary relations (as, for example, when a knowledgeable adult tutors a remedial student) (Lepper et al., 1990, 1997) and sometimes in more symmetrical relations (as, for example, when classroom 
peers work well together, each facilitating the individual learning of the other) (Slavin, 1994).

How does this version of social mediation work, and what does it yield? When does the social context facilitate learning, and when does it fail to do so? The theoretical underpinnings of the socially mediated learning of the individual were greatly influenced by Vygotsky's conception of the zone of proximal development. According to this conception, external social processes become internalized to serve in a mental capacity, thereby raising the level of individuals' cognitive performance to one they could not have reached on their own (Vygotsky, 1978). Whether directly inspired by Vygotskian thinking or by more current constructivist sources, social "scaffolding" (Scardamalia, Bereiter, McLean, Swallow, \& Woodruff, 1989) entails two critical processes: internalization and active construction of knowledge in the form of active solutions to problems or formulation of designs, with the help of explicit guidance, modeling, encouragement, mirroring, and feedback (e.g., Brown \& Palincsar, 1989; Perkins, 1991; Slavin, 1994).

The importance of active, constructive participation is underscored by an interesting difference between tutoring and peer problem solving. Whereas adult tutors aim to facilitate the learning of their tutees, peers working together often aim simply to accomplish the task. Consequently, the individual learner often has more of a chance to participate actively in critical planning and decision making when interacting with an expert tutor than with peers (Rogoff, 1991). This highlights an important aspect of social mediation of individuals' learning: Mediation is effective not necessarily as a function of simple "internalization, with modeled information being transferred across a barrier from a social partner to the inside of a child, or with information being transmitted" (Rogoff, 1991, p. 362). Rather, mediation is effective through active participation whereby learners "transform their understanding and skill in solving the problem" (Rogoff, 1991, p. 362). Thus, according to this view, it is active construction that is so crucial to learning, not some social guidance going underground. It becomes clear why social learning and a constructivist approach to learning have become close allies (Resnick, 1991).

Lepper and his colleagues emphasize this theme in their analyses of expert tutors, who routinely attain impressive progress in mathematics with remedial, failure-prone, and math-phobic students within a single session (Lepper et al., 1990, 1997). Many of the features that distinguish such expert tutors from their less effective colleagues are those that characterize social facilitation of individuals' learning in general: intensive interaction, rapid feedback, highly personalized and situationally contingent guidance, encouragement, and the elicitation of responses from the student in the form of explanations, suggestions, reflections, and considerations rather than the provision of ready-made information, directions, error corrections, or answers. Effective social facilitation through teamwork, although it occurs less reliably, appears to share the same characteristics.

As these points make plain, this perspective on social learning involves the critical conditions for an effective learning system mentioned earlier. Most important, social mediation of learning by tutors or peers, when well conducted, can meet these conditions far more effectively than its solo learning alternative. In fact, some of 
the conditions we have mentioned are, by necessity, socially based and cannot be easily met by most learners without the facilitating social context: informative feedback, challenge, guidance, and encouragement.

There are further characteristics that distinguish socially mediated learning from relatively solitary learning to the advantage of the former. One such condition involves the "objectivization" of one's thoughts, still-to-be-formulated ideas, and considerations, which, when communicated and shared, can be discussed, examined, and elaborated upon as if they were external objects. Objectivization of this sort is quite impossible outside the social context. Slavin (1994) pointed to two additional conditions necessary for social mediation to be effective: shared group goals and personal accountability. In his review of the research literature, he found that, in their absence, no significant enhancement of learning takes place; members of the learning system may work in incongruent directions and may not expend the needed mental effort (for other factors that debilitate social facilitation, see O’Donnell \& O'Kelly, 1994; Salomon \& Globerson, 1987).

\section{Social Mediation as Participatory Knowledge Construction}

The account of social mediation reviewed so far has two features that some would view with suspicion. First, the notion that cognitive processes can be socially mediated suggests that these same processes, under the right conditions, might proceed without such mediation. Second, by and large the focus has fallen on the learner's learning, without a recognition that the facilitating social agent also may learn.

These concerns have led to a different conceptualization of social mediation influenced by the more qualitative, holistic way of anthropological thinking; the neo-Vygotskian sociocultural school of thought; and a sharp critique of typical laboratory learning studies as too removed from the social context of real life. Especially motivating are systematic findings about the nonsystematicity of human performance, so highly dependent on particular cultural and social situations (e.g., Lave \& Wenger, 1991). Such factors led to the development of a new paradigm for the study of learning in social contexts (e.g., Lave, 1988; Resnick, 1991; Wertsch, Del Rio, \& Alvarez, 1995). According to Wertsch (1991), the basic assumption of this sociocultural paradigm is as follows:

Human mental functioning is inherently situated in social interactional, cultural, institutional, and historical context. Such a tenet contrasts with approaches that assume, implicitly or explicitly, that it is possible to examine mental processes such as thinking or memory independently of the sociocultural setting in which individuals and groups function. (p. 86)

Given the relative novelty of the sociocultural approach, much of its vocabulary and many of its basic constructs are still somewhat vague; it is not easy "to refer to them as a mature scientific paradigm with generally accepted theoretical foundations, a methodology, and a well-delineated set of prescriptions for relating theory to practice" (Cole, 1995, p. 187). Nevertheless, the basic ideas are relatively clear: It becomes unreasonable to separate cognition or motivation from the socially mediating context or, for that matter, to separate individuals from their activities 
and the contexts in which they take place. As stated by Resnick (1991): "We seem to be in the midst of multiple efforts to merge the social and cognitive, treating them as essential aspects of one another rather than as dimly sketched background or context" (p. 3).

Indeed, new composite units of analysis have emerged for study and design. Cognitive activity, goal, social interactions, and learning materials are seen as a merged unit uniquely situated in a particular context. The base paradigm is the historical event in which events and contexts are necessarily and inevitably interwoven (Hickey, 1997). The unit of analysis is the interpsychological functional system composed of interacting individuals, situations, activities, contents, and meanings (Newman, Griffin, \& Cole, 1989). According to Sfard (in press), "the identity of an individual...is a function of her being (or becoming) a part of a greater entity. Thus, talk about stand-alone learner and decontextualized learning becomes as pointless as the attempts to define lungs and muscles without a reference to the living body within which they both exist and function."

Despite these contrasts with the social mediation of individual learning, the notion of learning systems as information-processing systems that must meet critical conditions of information provision, feedback, and so on still makes sense. However, the description of a learning system changes. Knowledge, rather than being transmitted or internalized, becomes jointly constructed ("appropriated") in the sense that it is neither handed down ready-made nor constructed by individuals on their own. Rather, knowledge, understandings, and meanings gradually emerge through interaction and become distributed among those interacting rather than individually constructed or possessed (Pea, 1993). And if knowledge is distributed among participants in a specific activity context, it is necessarily situated as well (Greeno, 1997), that is, intimately welded to the context and the activity in which and by means of which it is constructed. Therefore, participation becomes the key concept (as contrasted with acquisition and conceptual change) serving as both the process and the goal of learning (Sfard, in press).

Greeno (1997) asks whether we should "consider the major goals and outcomes of learning primarily as collections of sub-skills or as successful participation in socially organized activity and the development of students' identities as learners" (p. 9). The answer to this question from a sociocultural point of view clearly favors the latter: The name of the game is participation, and it stands in stark contrast to the decontextualizable cognitive attainments of the individual (Cole, 1991; Sfard, in press), as often-and, apparently, incorrectly — attributed to Piaget (Lourenço \& Machado, 1996). Whereas accounts of learning offered from Piagetian or traditional information-processing perspectives emphasize individuals' (solo) knowledge construction, often facilitated by social scaffolding, the socioculturally inspired account emphasizes the socially based participatory construction of knowledge. And whereas the former views learning and knowledge as pertaining mainly to individuals' transferable cognitive attainments, the latter sees learning more as a highly situated activity of participation (cf. Anderson, Reder, \& Simon, 1996; Greeno, 1997).

These differences between the situative and cognitive approaches can perhaps best be illustrated by the differences in the instructional design implications that 
follow from each. In the situative approach, social knowledge construction develops distributed knowledge, skills, and understandings around the target activity system. What is acquired is rather "holistic," and the hoped-for transfer is to other similar activity systems. In the cognitive approach, social knowledge construction serves individual knowledge construction. The aim is to equip the learner with portable chunks of knowledge, skill, and understandings that can serve in other contexts.

Emphasis on the situative approach raises serious questions about what in fact should be "taught" in school, the role the subject matter disciplines should play, and what criteria for evaluation should be used. After all, if effective participation is a major criterion, what would we consider the desired learning outcomes to be? But then, of course, such questions do not seem to be congruent with the main thrust of the sociocultural approach.

We thus have two versions of the basic idea concerning social mediation of learning. The more common one (the cognitive, acquisition-oriented version) views the social system enhancing the individual's learning as individual, striving to improve mastery of knowledge and skill. The more radical version (the situative, participation-oriented version) views the individual and the social agents as a unified learning system in which learning outcomes are both situated in the particular interactive context and distributed among the participants. In a later section, we attempt to interrelate the two.

\section{Social Mediation by Cultural Artifacts}

The role of tools and symbol systems as both reflecting and affecting the human psyche has long been recognized. But scholarly attention has focused on tools as social mediators of learning mainly as a result of the Russian sociocultural tradition of Vygotsky (e.g., 1978), Luria (1981), and Leont'ev (1981), along with their Western interpreters (e.g., Cole \& Wertsch, 1996). Here we use "tools" in a broad sense, including not only physical implements but technical procedures (e.g., the algorithms of arithmetic) and symbolic resources (e.g., those of natural languages and mathematical and musical notation).

A system formed by a person or persons using tools is not usually first and foremost a learning system. It is a system for doing something else, accomplishing some task like digging a ditch or having a conversation across an ocean. Nonetheless, any such system is secondarily a learning system, and at two levels. Hutchins (1996) points out how the conduct of an activity also characteristically involves development of the practitioners and development of the practice. The combination of persons and tools creates a new cognitive entity with an enriched cultural legacy and extended capabilities. The person may learn to use the tool more effectively, the tool and the objects to which it is applied thereby supplying information and feedback to that end, providing important conditions of learning, and helping to teach the user about a better way of accomplishing the task through the tool. Moreover, some tools mediate learning about a wide array of other matters. They may do so simply as information sources, as in the case of books or films, functioning as vehicles for symbolic communications. But more than that, they may do 
so as implements of information handling, as with a student's notebook and pencil (or, today, laptop computer), a flexible platform for organizing ideas expressed in the symbolic tools of text, formula, and diagram.

Tools characteristically play a double role: as means to act upon the world and as cognitive scaffolds that facilitate such action. Some tools not only enrich one's cognition but actually transform it. Memory is just not the same once certain language structures and writing have been acquired. The same applies to acquired ways of reasoning and to socially shared theories that constrain, color, and direct one's thinking and interpretation (e.g., Wertsch et al., 1995). For example, statistical tools are said to have become psychological models for the interpretation of human conduct (e.g., the analysis of variance model serving to explain human interaction) (Gigerenzer, 1991).

The cognitive transformations triggered by tools have two sides. One side is learning effects with the tool. This recognizes the changed functioning and expanded capability that takes place as the user uses and becomes accustomed to particular tools. Impact occurs through the redistribution of a task's cognitive load between persons and devices (e.g., Pea, 1993; Perkins, 1993), including symbol-handling devices (e.g., a spell check), or across persons, mediated by devices and symbol systems (telephones, fax machines). As these examples suggest, such tools are all around us, but their possibility also invites the design of special-purpose tools for supporting various cognitive functions. For instance, experiments have shown that a computerized "reading partner" that provides ongoing metacognitive-like guidance improves students' comprehension of texts while they read with the tool (Salomon, Globerson, \& Guterman, 1989).

In addition to effects with, there are effects of the tool. This concerns the more lasting ripple effects of using the tool beyond actual occasions of use: the impact on one's cognitive arsenal of skills, perspectives, and ways of representing the world (Salomon, Perkins, \& Globerson, 1991). Thus, for example, computer-based learning environments offer students "problem spaces" in which they can work through their understandings of challenging concepts (Perkins \& Unger, 1994). Students who read texts with the reading partner just mentioned have been shown to become better readers of novel, print-based texts and also better essay writers, apparently as a result of having learned to be more self-regulating (following the tool's model).

The contrast between of and with effects parallels, in some ways, the contrast between a cognitive, acquisition-oriented view of learning and a situative, participatory view. The acquisition stance emphasizes how tools can affect cognition in a relatively lasting and generalizable way even when people function in their absence. Thus, for example, Scribner and Cole (1981) studied the cognitive effects of literacy without schooling in the African tribe of the Vai, and Salomon (1994) studied the way in which elements of media symbol systems can become cognitive tools. On the other hand, as Olson, Torrance, and Hildyard (1985) have argued with respect to literacy, "It is misleading to think of literacy in terms of consequences. What matters is what people do with literacy, not what literacy does to people" (p. 15).

Thus, the "lessons" taught by tools involve not just the immediacies of changed 
performances while the tools are available but aspects of a culture's accumulated wisdom and intellectual history (Vygotsky, 1978). One cannot wield a screwdriver or write down an equation in a historically blank and culturally neutral way. Rather, "the history of a culture-an inherently social history - is carried into each individual act of cognition" (Resnick, 1991, p. 7). As argued by Cole and Wertsch (1996):

Higher mental functions are, by definition, culturally mediated. They involve not a direct action on the world, but an indirect action, one that takes a bit of material matter used previously and incorporates it as an aspect of action. Insofar as that matter itself has been shaped by prior human practice (e.g., it is an artifact), current action incorporates the mental work that produced the particular form of that matter. (p. 252)

A case in point is the introduction of computers into schools. Whereas computers were initially used as electronic workbooks for drill-and-practice purposes, it became apparent that, in fact, they tend to carry with them an entire educational philosophy of knowledge construction, symbol manipulation, design, exploration, and discovery (e.g., Sheingold, 1987). Although often assimilated to business-as-usual, in trend they serve as subversive instruments, their introduction promoting the restructuring of classroom learning environments, changes in teachers' ways of functioning, redefinition of curricula, and new ways of assessment.

Widely adopted tools often send certain "messages" about priorities through their presence. For instance, the ubiquitous use of the typewriter, and today keyboards and printers, signals the priority of legibility and speed over the personal touch of calligraphic style. The Macintosh interface, in contrast with the pre-Windows IBM interface, has been said to express a more human and "analog" view of how one might relate to computers. The spread of pasta machines, spell check devices, hand calculators, and computer-aided design programs sends the message that now, unlike in the past, "Everybody can do it without much learning." Learning was once required for those skills, sometimes even within a privileged guild, but no more. Such circumstances create a tension between - and sometimes heated debates about- the risks and losses of "deskilling" a practice versus the gains of convenience and accessibility.

\section{The Social Entity as a Learner}

The core notion of the social entity as a learner is that collective entities can learn. Such entities might include families (e.g., Moll, Tapia, \& Whitmore, 1993), high-performance teams (e.g., Hutchins, 1996), health organizations (e.g., Cole \& Engestrom, 1993), business organizations (e.g., Argyris, 1993; Argyris \& Schon, 1996; Senge, 1990), and more. Close attention to the social entity as a learner might strike some as odd in this overview of social learning with educational issues and agendas in mind. After all, the principal learners in schools are not groups but individuals, even if team-learning techniques are sometimes used. However, such a reaction mistakes both the scope of learning and that of education as developed here. Not only does a great deal of individual learning and education occur outside of schools; just as families, teams, corporations, and other organizations can be said to learn, so one can speak of educating them. Family therapy sessions or prebirth 
child-care sessions educate families, not just the individuals involved. Coaches and trainers educate teams of athletes. Corporate consultants concerned with organizational learning might reasonably be said to educate the corporations whose practices they improve. It is within the compass of this broad view of learning and education that the inquiry proceeds.

With this said, it is also true that the learning of social entities takes a decisive step away from the literature of earlier sections. The scholars concerned with the learning of social entities constitute, by and large, a camp of their own. A number of other shifts are notable. The social entity typically, although not always, has to learn on its own, subject to its own autoregulation. When there is a "teacher," usually the relationship is not one to many, as in a classroom, but one to one, as with a coach and team or a consultant addressing the needs of an organization. Whereas a common problem with individual learning is its desituated character, most learning of social entities is well situated. Sports teams, for example, do not study and practice for years before starting true play. Corporations do not apprentice to other corporations for years before making a go on their own. Finally, at a conceptual level, concepts such as learning, memory, models and modeling, reinforcement, trial and error, and so on need to be reinterpreted in the context of social entities.

With such differences in mind, three questions are particularly apt for a brief analysis of the learning of social entities: What is learned? How is it learned? And how can it be learned better? For all three questions, it is also important to examine whether the answers involve any distinctively social characteristics or amount to straightforward extrapolations from the case of the individual learner.

As to what is learned, Huber (1989) suggests that learning consists in knowledge, in a broad sense, acquired by any unit of an organization and available for acting upon. Superior learning lies in knowledge more widely distributed across units, with common rather than disparate interpretations. Huber, following Morgan and Ramirez (1983), writes of such knowledge as "holographic," in that each unit carries at least a rough picture of the whole.

Levitt and March (1988) advanced organizational routines as the stuff of organizational learning, including policies and practices and their underlying belief systems. By definition, acquiring new routines represents a change in overt behavior, a requirement Huber does not make. Weick (1979) pointed to emerging agreements about standard operating procedures, what is right or wrong in the organizational conduct, and the meanings to be assigned to whatever the organization does. Trying to define an orchestra, he wrote:

If we then ask where [the] orchestra is, the answer is that the orchestra is in the minds of the musicians. It exists in the minds of the musicians in the form of the variables they routinely look for and the connections they routinely infer among these variables. (p. 141)

Similarly, Argyris and Schon (1996) focus on stable changes in organizational behavior. Cole and Engestrom (1993) offer an analysis of activity systems that specifies several loci within which organizational learning can occur, such as the prevailing rules, the division of labor, the mediating artifacts (both physical and conceptual), the aims of the enterprise, and, of course, individual learners. 
While some differences are apparent among such views, they are, by and large, compatible. It is also clear that all entail distributions of knowledge only partly analogous to those in the mind of an individual. We do not ordinarily consider possession of an artifact knowledge, yet possession of a database constitutes a kind of organizational knowing. Patterns of division of labor within an organization are kinds of know-how that have no easy individual analog. As noted earlier, knowledge possessed by individuals or larger units about how to coordinate with other units in a particular organization is a distinctively social kind of knowledge.

A second question was how learning occurs. Here it is useful to turn back to the notion of a learning system. One function of a learning system is generation of new representations and behaviors. Within collectives, this can certainly occur through individuals or groups evaluating current practices and goals, reflecting, and devising new plans. It can also occur through "grafting," as an organization acquires new personnel or purchases data sets (Huber, 1989). Imitation of various kinds is a commonplace mechanism of learning in groups, as in individuals. In groups, collective patterns of behavior may be imitated, such as a new division of labor pattern (Levitt \& March, 1988). Productive variation may be stimulated by "organizational slack" that makes room for accidental variations and casual experiments (Levitt \& March, 1988).

Feedback on old or new structures and practices commonly takes the form of assessment of performance against such distal goals as bottom-line profit and such proximal goals as people's happiness or divisional efficiencies. Comparison with the performance of other departments within an organization or other organizations can generate feedback and almost inevitably does so in competitive situations. Levitt and March (1988) argue that an organization's history wields a much more powerful selective influence than speculative feedback based on exploration of conjectural scenarios. Another source of feedback derives from comparison of current structures and practices with conceptual models promulgated by the literature and consultants.

While other aspects of a learning system could be examined, these examples of generation of alternatives and of feedback suffice to point out some characteristics of organizational learning and make the case that it involves distinctive features. Grafting, for example, has no straightforward analog in the individual learner, nor do processes of the social distribution of knowledge across various units and individuals.

If organizations can learn, this does not mean that they learn very efficiently. A strong theme in the literature on organizational learning is the weakness of the learning system involved. The learning of the collective suffers from a startling range of limitations (Argyris, 1993; Argyris \& Schon, 1996; Huber, 1989; Levitt $\&$ March, 1988). Some of these limitations are equally characteristic of individual and collective learning entities. For instance, rare high-stakes events (e.g., an individual's marriage decision or major shifts of direction in a business) are difficult learning targets because they do not occur often to disambiguate the lessons of experience and because by the time they occur again, circumstances may have changed substantially. 
Other problems in terms of learning are exacerbated by the specifically organizational character of the learning. For example, different individuals and units within an organization may hold somewhat different criteria of success. Also, advocates of a policy are likely to interpret any difficulties with it as reflecting an insufficiently vigorous pursuit of the policy, while opponents interpret the same data as signifying a bad policy. Feedback about the results of organizational actions may be distorted or suppressed as people rush to protect their turf or to maintain a positive climate. Argyris and Schon (1996) argue that self-sealing systems of beliefs arise in organizations because individuals behave toward one another in ways that pursue agendas while concealing them and because individuals aim unilaterally to protect both themselves and others against the distress of negative feedback. Under such circumstances, "single-loop learning" can still occur (accomplishing refinements in conduct without change in the underlying belief systems), but not "double-loop learning" (which involves making explicit and reconsidering tacit theories-in-use).

One broad systemic characteristic amplifies many of these problems: Organizational learning systems tend to take the "low road" (Salomon \& Perkins, 1989). Learning occurs without any "high road" mindfulness or reflective abstraction. One or another problem is identified and a plan adopted, one or another individual gains more influence, one or another practice is reinforced as much by accidental circumstances as by any reliable consequences. Hutchins (1996) characterizes a great deal of organizational learning as more like a blind evolutionary process than deliberate design. This low road rather than high road character of organizational learning should not come as a surprise. After all, first and foremost organizations are performance systems, not learning systems.

In consequence, much of the contemporary literature on organizational learning focuses on how to make such learning function better. Broadly speaking, the aim is to introduce more of a high road learning process in which learning becomes a conscious and deliberate agenda of the organization alongside other more traditionally identified organizational functions. For example, Argyris and Schon (1996) focus on helping organizations to solve problems and take opportunities in ways that yield double-loop rather than single-loop learning. This involves helping individuals to air and test tacit assumptions publicly, avoid unilateral protection of themselves or others, and come together in collective problem-solving processes that deal with large-scale tacit issues, not just surface technical issues.

Epistemology is a strong theme in such initiatives (Argyris \& Schon, 1996; Senge, 1990). Both leaders and followers in organizations tend to harbor broad impressionistic beliefs about what has happened or how to get things done that thrive on mechanisms of self-fulfilling prophecy but have at best a limited foundation in reality. Accordingly, interventions commonly foreground varieties of belief testing that look to hard data or a finer grain of informal observation.

Still another theme is that people attempting to guide organizations commonly do not understand organizational dynamics and need better mental models. Thus, interventions often try to introduce new conceptions of organizational dynamics. Senge (1990) foregrounds systemic aspects of organizational dynamics, introduc- 
ing a range of "system archetypes" that capture typical but neglected patterns of interaction, such as repairs that backfire in the long run or the tragedy of the commons. Stacey (1992) emphasizes the chaotic characteristics of organizational dynamics and urges anchoring thinking in the here and now, avoiding too uniform an organizational culture, and developing a constantly evolving agenda rather than a long-term, stable vision. Argyris and Schon (1996) aspire to raise awareness of self-sealing interactions and shift an organization's models of learning toward double-loop practices that allow regular reexamination of underlying concepts and commitments as a part of problem solving and opportunity taking.

In summary, organizations, like individuals, can learn. Many of the fundamental phenomena of learning are the same for organizations. Not only the general characteristics inherent to any learning system but particular phenomena such as the troublesomeness of high-stakes rare events are common to both. However, organizational learning also has distinctive characteristics with reference to what is learned, how it is learned, and the adjustments called for to enhance learning. These characteristics derive from the fact that any organization by definition is a collective, with individuals and larger units in different roles that involve different perspectives and values, passing information through their own filters, and with noisy and loss-prone information channels connecting them.

Under such circumstances, it is hardly surprising that organizational learning would have a number of characteristic emergent features. In contrast with the mixed character of individual learning discussed earlier, the learning of social entities tends strongly to be low road and situated. "Teaching" occurs much less frequently than in the individual case. The high road of autoregulation is often virtually absent. Finally, the social entity can often be divided against itself, with different tacit beliefs and concealed agendas harbored by different subgroups or individuals. Of course, none of these phenomena are entirely absent from the individual case. For instance, one of the great lessons from Freud was that an individual mind can be divided against itself. Nonetheless, a number of contrasts in trend are conspicuous.

\section{HOW INDIVIDUAL AND SOCIAL LEARNING RELATE}

We began by asking whether social learning is a meaningful concept, sufficiently distinct from individual learning to warrant attention. Our answer is an emphatic yes. As elaborated earlier, there is ample evidence to show that individuals' learning is facilitated by others, that meaning is often socially constructed, that tools serve as mediators, and that social systems as organic entities can engage in learning much as individuals do.

With the reality of social learning acknowledged, it is tempting to say that the tables have been turned on the notion of individual learning. Far from social learning being a questionable appendix to individual learning, individual learning itself is a suspect phenomenon. Thus, as some would argue, there is in reality no individual learning to speak of. Virtually anything one learns, according to the sociocultural view, comes deeply embedded in a cultural context, involves culturally informed and laden tools, and figures as part of a range of highly social activity systems, however alone the learner may be at particular moments. 
All of this may be true enough, but dismissing the notion of individual learning altogether would be to throw out the baby with the bath water by blurring important distinctions. Individual learning is most sensibly viewed not as learning utterly naked of social contexts, influences, and participations but as learning in which the factors discussed earlier have relatively lesser rather than greater presence. Matters of degree and level of analysis are involved. Thus, the anthropologist Sperber (1984), discussing the relationships between culture and cognition, compared them with the relationships between epidemiology and cell biology. One of his main points was that epidemiology cannot be reduced to cell biology, and vice versa. Rather, each needs to be considered as an entity or process in its own right. In Sperber's spirit, we need to ask how individual and social learning relate to one another. Our answer takes the form of three propositions.

Relation 1: Individual learning can be less or more socially mediated learning. While almost all individual learning is social in some sense, the degree of active social mediation may vary considerably from situation to situation. The young basketball player practicing foul shots for hours alone enjoys relatively little social mediation during that period, although, of course, the activity occurs within the larger context of a highly social endeavor. The same basketball player practicing with team members and a coach functions in a highly socially mediated setting. The same point can be expressed from the perspective of situated or participatory learning. The basketball player's activities are always situated within the larger activity system of basketball, even during solo practice. But during solo practice, that larger system impinges only through the player's memories and the physical structure of the court, not through the immediate words and actions of the other players and coach.

Moreover, if at the individual end of the spectrum social factors still figure, it is likewise so that at the social end of the spectrum, in contexts of active social mediation, the learner remains - and should remain - an individual learner in significant ways. Perkins (1993), while arguing generally for the distributed character of cognition, notes that regulative functions need to be managed by the learner to some extent, or else the learner will not develop autoregulative cognitions. Learners who are constantly scaffolded in the management of their learning are less likely to develop such capacities. Bereiter (1997; Bereiter \& Scardamalia, 1989) argues that some learners take the opportunity to engage in more intentional and deeper learning, above and beyond the affordances of the social situation and what it calls for. As pointed out by Damon (1991):

Even when learning is fostered through processes of social communication, individual activity and reflection still play a critical role. Sometimes...individual activity may build on collective questions and insights. Other times, however, individual activity actually may need to resist the collective illusions created by a group.... Any paradigm that assumes a one-way, deterministic relation between the collective and individual knowledge construction is overly simplistic. (p. 392)

Finally, it is worth noting that while the social end of the continuum may have been neglected in many earlier developmental, cognitive, and behaviorist studies, and important phenomena passed over, those studies proved fruitful in other ways. Many valuable insights about cognition and learning have emerged from labora- 
tory investigations of individuals learning as individuals. For some purposes, such as the focused examination of particular learning processes of self-regulation, the detailed study of misconceptions in science, or the analysis of basic neuropsychological processes of learning, this may be a better approach than a more socially oriented one.

Relation 2: Individuals can participate in the learning of a collective, sometimes with what is learned distributed throughout the collective more than in the mind of any one individual. A further sense of social learning is the learning of social entities. This sense generates another relationship between individual and social learning. To return to the case of the basketball player, the individual player, even during solo practice, is not only learning in his or her own behalf but acquiring skills that strengthen the team. At moments of practicing together or planning together, the team learns collective skills such as rapid coordination, many of which cannot be reduced to the skills of any one individual but have to do with the way they work together. By hiring a star player, the team may learn through "grafting" (Huber, 1989), in which no individual involved acquires new knowledge and skill, but the team does.

Note that the learning of a team or other collective entity, like the learning of an individual, can itself be more or less mediated by social factors outside the entity. In other words, the first continuum applies to both. In the case of the basketball team, a mediating "other" might be a coach or an opposing team.

Relation 3: Individual and social aspects of learning in both senses (Relations 1 and 2) can interact over time to strengthen one another in what might be called a "reciprocal spiral relationship." A third answer to the question of how individual and social learning interrelate suggests that the two complement each other in a spiraling dynamic of reciprocal influences. Individual and social causes became influenced by their own consequences and, sometimes, even defined by them (Bronfenbrenner, 1977; Weick, 1979). This notion extends Sfard's (in press) suggestion that individual and social conceptions of learning be considered side by side to exploit the advantages of each and as a protection against theoretical excesses.

To sharpen the idea, let us trace a couple of these spiral reciprocities. A student experiencing difficulties with mathematics may benefit from joint problem-solving sessions with a group of peers (active social mediation of learning), with student and peers reaching, through negotiations, several understandings concerning the way they want to proceed (the social entity learning to function), which leads to a certain division of labor concerning homework to be done by each member (but with mediation by cultural artifacts such as textbooks). The student then returns the next day to the group of peers to compare notes with his or her partners and to jointly solve new and more demanding problems (further active social mediation of a different sort, with the team members having progressed in their math understanding).

In other words, the student learns through different learning systems with varying degrees of social mediation and collectivity at different moments, with their characteristic ways of providing information, generating feedback, and so forth. 
For the student—indeed, for all participants—-these different learning systems are symbiotic. They benefit one another. Students may learn more efficiently and thus reach a deeper understanding of the subject matter at hand, an achievement they will walk away with as their own, while the team may learn to learn better as a team through participation in such spirals (e.g., Bereiter, 1997).

A further example turns from the world of schools to the world of business. A manufacturing company's sales slump raises a general readiness for changes in the company's business practices. With such a readiness "in the air," a member of a financial planning team for the company collaborates in discussions mapping probable sales changes for the upcoming year (learning as participation), accepts the assignment of investigating the projected cost of key materials and begins by consulting a range of sources in books and on the Internet (individual learning supported by cultural artifacts), discusses questions with a professional consultant (social mediation of individual learning), and returns to the group to meld the insights gained into the collective understanding of the group. The suggested changes, now shared by the management, filter down through the organizational grapevine, triggering excitement and gradually becoming a new kind of standard operating procedure (learning of a social entity). As in the case of the student, the different learning systems with their different ways of meeting the critical conditions of learning are symbiotic. The spiral through them benefits the individual and the collective alike.

A further large-scale characteristic of individual and social learning deserves note here. It is not just that learners learn better through the reciprocities between different learning systems. More than that, the patterns of reciprocity themselves evolve; the reciprocity itself "learns," so to speak. When individuals enter a social learning situation, they take away from it not only knowledge about the topic at hand but knowledge about how to manage such situations. Likewise, the team, group, classroom, teacher, or tutor changes as well, affected by the other members of the interaction. Or consider the example of a research team. While its members enter the team's planning meeting with their own knowledge, dispositions, preferences, attitudes, and preconceived notions about the research question and methodology, the team's deliberations might well result in an agreed-upon agenda, focused questions, division of labor, and even a team's uplifting spirit. Now each member goes home and ponders the deliberations, reconsidering his or her position and way of relating to the others. One of them might, for example, take notice of the fact that another member tends to dominate the discussions and, hence, decide to introduce turn-taking procedures. Each change taking place on one occasion colors the interactions on subsequent occasions, thus allowing for developmental continuity (Damon, 1991). Hence, the reciprocal relationship is all the more a spiral one (Salomon, 1993).

Spiral reciprocity is less evident in the sociocultural approach to social learning, in which the learning system is a social system without a clear demarcation between individual learner and social agent. The argument made is that cognitions, themselves socially distributed, are inseparable from the socially based activity and from the tools used. As stated by Cobb (1997), "There is no need to equip 
individuals with tools or to place them in social context for the simple reason that individuals do not act apart from tools and contexts" (p. 174). However, we still think that the argument made by Damon (1991) applies here as well. Although, according to the sociocultural, participatory view, the different components of the learning system may not exist without each other (Cobb, 1997), which is the essence of being a fully integrated social system, we believe that each still retains its separate identity and attributes as an individual, as a team, or as a tool.

\section{IMPLICATIONS FOR THE DESIGN OF INSTRUCTION}

A great deal of learning occurs without instruction. The toddler struggling to climb onto a couch, the car shopper sizing up competing vehicles, the newly formed management team getting to know one another, are all in the midst of learning, but no teacher or instructional plan shapes their learning. Broadly speaking, instruction is designed learning, learning mediated not by fortunate circumstances but by intentional design. When a parent helps the toddler just barely enough, an article advises the car shopper, a book or workshop provides the members of the management team with good initial steps to follow, then we have instruction. When the design of instruction is guided by systematic and validated principles and theories, instruction becomes a design science (Perkins, 1992).

The present analysis of individual and social learning argues that this design science needs to be conceived on a wider scale. If collectives such as teams and corporations can learn, it makes sense to speak of instructing them, of establishing carefully designed conditions that favor their learning. Instruction involves collectives as well as individual learners. Moreover, the present analysis of social learning also informs the kinds of designs that would serve best.

Earlier we emphasized that effective learning of any scope involves not one learning system but several functioning together in spirals of reciprocity. Well-designed instruction therefore involves different learning systems at different moments in synergistic interaction. Admittedly, this formula is broad. Its concrete implications become plainer when one looks to the rather impoverished spirals characteristic of many school settings, for example, the routine seesaw system between the teacher interacting didactically with many students and the lone student in front of a textbook or worksheet. Innovative instruction of virtually any sort involves a dramatic enrichment of this seesaw model with more varied and intricate spirals of reciprocity.

Another implication of the discussion is that good learning, whether individual or collective, depends greatly on self-mediation or mediation by other agents; in other words, it depends on high road (intentional, conceptually oriented) rather than low road (practice and automaticity-oriented) learning (Salomon \& Perkins, 1989). Typical school settings do not offer nearly the opportunities they might for the development of self-regulated, high road learning. If anything, the problem is even more acute for the learning of large collective entities such as corporations, which characteristically have little "metacognitive" awareness of their own learning. The collective that worries about mediating its own learning and the learning of individuals within it is far more likely to learn better and foster individual learning. 
Relatedly, the development of autoregulation of learning in individuals and collectives needs to include attention to the social nature of learning. It is not enough to learn to direct one's own learning as an individual learner abetted by artifacts such as textbooks. Learning to learn in an expanded sense fundamentally involves learning to learn from others, learning to learn with others, learning to draw the most from cultural artifacts other than books, learning to mediate others' learning not only for their sake but for what that will teach oneself, and learning to contribute to the learning of a collective. If the reciprocal spiral described earlier has any validity, then an individual's contribution to the learning of the collective is likely to benefit the individual as well.

If all of this seems like a celebration of the potentials of social learning, it is-up to a point. However, the dark side of such interactions also has to be recognized. What is learned by an individual may upset or even subvert rather than abet collective ends, as with the student taking advantage of his or her team members' work or the corporate climber being more interested in personal advancement than in the overall success of the organization. What is learned by the collective does not necessarily benefit the individual learners, as when a teacher forms a tacit contract with students (e.g., "I won't ask too much if you do the little I ask") or a limited conception about learning takes sufficient hold in particular populations (e.g., a team of students reaches an agreement to pretend to work but, in fact, gangs up on the teacher to do as little as possible) (Salomon \& Globerson, 1987). In such cases, the collective has "learned," but what it has learned happens to be profoundly limiting both for itself and for the participating individuals.

The remedy for such pitfalls lies in the concept of instruction as designed learning. Cautionary examples such as the foregoing occur along the "low road," where the goals and processes of learning receive no autoregulative attention from the agencies involved. While haphazard learning has served the human species and many others well enough, one of our most important achievements as a species must certainly be the many "high road" ways we design learning for one another, and indeed for ourselves, individually and collectively. Recognition of the social side of learning in one sense complicates the challenge of instruction by introducing more choices to be made. But it also enriches the instructional palette with which we attempt to paint our own future selves.

\section{REFERENCES}

Anderson, J. R., Reder, L. M., \& Simon, H. A. (1996). Situated learning and education. Educational Researcher, 25(4), 5-11.

Argyris, C. (1993). On organizational learning. Cambridge, MA: Blackwell.

Argyris, C., \& Schon, D. A. (1996). Organizational learning II: Theory, method, and practice. New York: Addison-Wesley.

Bandura, A. (1989). Human agency in social cognitive theory. American Psychologist, $44,1175-1184$.

Bereiter, C. (1997). Situated cognition and how to overcome it. In D. Kishner \& J. A. Whitson (Eds.), Situated cognition: Social, semiotic, and psychological perspectives (pp. 281-300). Hillsdale, NJ: Erlbaum. 
Bereiter, C., \& Scardamalia, M. (1989). Intentional learning as a goal of instruction. In L. B. Resnick (Ed.), Knowing, learning, and instruction: Essays in honor of Robert Glaser (pp. 361-392). Hillsdale, NJ: Erlbaum.

Bronfenbrenner, U. (1977). Toward an experimental ecology of human development. American Psychologist, 32, 513-531.

Brown, A. L., \& Palincsar, A. S. (1989). Guided, cooperative learning and individual knowledge acquisition. In L. B. Resnick (Ed.), Knowing, learning, and instruction: Essays in honor of Robert Glaser (pp. 393-451). Hillsdale, NJ: Erlbaum.

Chipman, S. F., Segal, J. W., \& Glaser, R. (Eds.). (1985). Thinking and learning skills: Vol. 2. Research and open questions. Hillsdale, NJ: Erlbaum.

Cobb, P. (1997). Learning from distributed theories of intelligence. In E. Pehkonen (Ed.), Proceedings of the 21st Conference of the International Group for the Psychology of Mathematics Education (Vol. 2, pp. 169-176). Lahti, Finland: University of Helsinki.

Cole, M. (1991). Conclusion. In L. B. Resnick, J. M. Levine, \& S. D. Teasley (Eds.), Perspectives on socially shared cognition (pp. 398-417). Washington, DC: American Psychological Association.

Cole, M. (1995). Sociocultural settings: Design and intervention. In J. V. Wertsch, P. Del Rio, \& A. Alvarez (Eds.), Sociocultural studies of mind (pp. 187-214). New York: Cambridge University Press.

Cole, M., \& Engestrom, Y. (1993). A cultural-historical approach to distributed cognition. In G. Salomon (Ed.), Distributed cognitions: Psychological and educational considerations (pp. 1-46). New York: Cambridge University Press.

Cole, M., \& Wertsch, J. V. (1996). Beyond the individual-social antinomy in discussions of Piaget and Vygotsky. Human Development, 39, 250-256.

Damon, W. (1984). Peer education: The untapped potential. Journal of Applied Developmental Psychology, 5, 331-343.

Damon, W. (1991). Problems of direction in socially shared cognition. In L. B. Resnick, J. M. Levine, \& S. D. Teasley (Eds.), Perspectives on socially shared cognition (pp. 384 397). Washington, DC: American Psychological Association.

De Vries, R. (1997). Piaget's social theory. Educational Researcher, 26(2), 4-17.

Gardner, H. (1985). The mind's new science: A history of the cognitive revolution. New York: Basic Books.

Gigerenzer, G. (1991). From tools to theories: A heuristic discovery in cognitive psychology. Psychological Review, 98, 254-267.

Greeno, J. G. (1997). Response: On claims that answer the wrong question. Educational Researcher, 20(1), 5-17.

Hickey, D. T. (1997). Motivation and contemporary socio-constructivist instructional perspectives. Educational Psychologist, 32, 175-193.

Huber, G. P. (1989, March). Organizational learning: An examination of the contributing processes and a review of the literature. Paper presented at the Conference on Organizational Learning, Pittsburgh, PA.

Hutchins, E. (1996). Cognition in the wild. Cambridge, MA: MIT Press.

Lave, J. (1988). Cognition in practice. New York: Cambridge University Press.

Lave, J., \& Wenger, E. (1991). Situated learning: Legitimate peripheral participation. New York: Cambridge University Press.

Leont'ev, A. N. (1981). Problems in the development of mind. Moscow: Progress.

Lepper, M., Aspinwall, L., Mumme, D., \& Chabay, R. (1990). Self-perception and social perception processes in tutoring: Subtle social control strategies of expert tutors. In J. M. Olson \& M. P. Zanna (Eds.), Self-inference processes: The Ontario Symposium (Vol. 6, pp. 217-237). Hillsdale, NJ: Erlbaum.

Lepper, M. R., Drake, M. F., \& O'Donnell-Johnson, T. (1997). Scaffolding techniques of expert human tutors. In M. Pressley \& K. Hogan (Eds.), Advances in teaching and learning (pp. 108-144). New York: Brookline Press. 
Levitt, B., \& March, J. G. (1988). Organizational learning. Annual Review of Sociology, 14, 319-340.

Lourenço, O., \& Machado, A. (1996). In defense of Piaget's theory: A reply to 10 common criticisms. Psychological Review, 103, 143-164.

Luria, A. R. (1981). Language and cognition. Washington, DC: Winston.

Moll, L. C., Tapia, J., \& Whitmore, K. P. (1993). Living knowledge: The social distribution of cultural resources for thinking. In G. Salomon (Ed.), Distributed cognitions: Psychological and educational considerations (pp. 139-163). New York: Cambridge University Press.

Morgan, G., \& Ramirez, R. (1983). Action learning: A holographic metaphor for guiding social change. Human Relations, 37, 1-28.

Newman, D., Griffin, P., \& Cole, M. (1989). The construction zone: Working for cognitive change in school. New York: Cambridge University Press.

O'Donnell, M., \& O' Kelly, J. (1994). Learning from peers: Beyond the rhetoric of positive results. Educational Psychology Review, 6(4), 321-349.

Olson, D. R., Torrance, N., \& Hildyard, A. (Eds.). (1985). Literacy, language and learning. New York: Cambridge University Press.

O’Neil, H. F., \& Spielberger, C. D. (Eds.). (1979). Cognitive and affective learning strategies. New York: Academic Press.

Pea, R. D. (1993). Practices of distributed intelligence and designs for education. In G. Salomon (Ed.), Distributed cognitions: Psychological and educational considerations (pp. 47-87). New York: Cambridge University Press.

Perkins, D. N. (1986). Knowledge as design. Hillsdale, NJ: Erlbaum.

Perkins, D. N. (1991). Technology meets constructivism: Do they make a marriage? Educational Technology, 31(5), 18-23.

Perkins, D. N. (1992). Smart schools: From training memories to educating minds. New York: Free Press.

Perkins, D. N. (1993). Person plus: A distributed view of thinking and learning. In G. Salomon (Ed.), Distributed cognitions: Psychological and educational considerations (pp. 88-110). New York: Cambridge University Press.

Perkins, D. N. (1995). Outsmarting IQ: The emerging science of learnable intelligence. New York: Free Press.

Perkins, D. N., \& Unger, C. (1994). A new look in representations for mathematics and science learning. Instructional Science, 22, 1-37.

Pressley, M., \& Brainerd, C. J. (Eds.). (1985). Cognitive learning and memory in children: Progress in cognitive development research. New York: Springer-Verlag.

Resnick, L. B. (1991). Shared cognition: Thinking as social practice. In L. B. Resnick, J. M. Levine, \& S. D. Teasley (Eds.), Perspectives on socially shared cognition (pp. 1-20). Washington, DC: American Psychological Association.

Rogoff, B. (1991). Social interaction as apprenticeship in thinking: Guided participation in spatial planning. In L. B. Resnick, J. M. Levine, \& S. D. Teasley (Eds.), Perspectives on socially shared cognition (pp. 349-364). Washington, DC: American Psychological Association.

Salomon, G. (1993). No distribution without individuals' cognition: A dynamic interactional view. In G. Salomon (Ed.), Distributed cognitions: Psychological and educational considerations (pp. 111-138). New York: Cambridge University Press.

Salomon, G. (1994). Interaction of media, cognition, and learning. Hillsdale, NJ: Erlbaum.

Salomon, G., \& Globerson, T. (1987). Skill is not enough: The role of mindfulness in learning and transfer. International Journal of Educational Research, 11, 623-637.

Salomon, G., Globerson, T., \& Guterman, E. (1989). The computer as a zone of proximal development: Internalizing reading-related metacognitions from a reading partner. Journal of Educational Psychology, 81, 620-627.

Salomon, G., \& Perkins, D. N. (1989). Rocky roads to transfer: Rethinking mechanisms of a neglected phenomenon. Educational Psychologist, 24, 113-142. 
Salomon, G., Perkins, D. N., \& Globerson, T. (1991). Partners in cognition: Extending human intelligence with intelligent technologies. Educational Researcher, 20, 2-9.

Scardamalia, K., Bereiter, C., McLean, R. S., Swallow, J., \& Woodruff, E. (1989). Computer-supported intentional learning environments. Journal of Educational Computing Research, 45, 51-68.

Scribner, S., \& Cole, M. (1981). The psychology of literacy. Cambridge, MA: Harvard University Press.

Segal, J. W., Chipman, S. F., \& Glaser, R. (Eds.). (1985). Thinking and learning skills: Vol. 1. Relating instruction to research. Hillsdale, NJ: Erlbaum.

Senge, P. (1990). The fifth discipline: The art and practice of the learning organization. New York: Doubleday/Currency.

Sfard, A. (in press). On two metaphors for learning and the dangers of choosing just one. Educational Researcher.

Sheingold, K. (1987). The microcomputer as a symbolic medium. In R. D. Pea \& K. Sheingold (Eds.), Mirrors of minds: Patterns of experience in educational computing (pp. 198-210). New York: Ablex.

Slavin, R. (1994). Cooperative learning: Theory, research, and practice (2nd ed.). Boston: Allyn \& Bacon.

Sperber, D. (1984, April). Anthropology and psychology: Toward an epidemiology of representations. Mallinowski Memorial Lecture presented at University of Paris.

Stacey, R. (1992). Managing the unknowable: Strategic boundaries between order and chaos in organizations. San Francisco: Jossey-Bass.

Tishman, S., \& Perkins, D. N. (1997). The language of thinking. Phi Delta Kappan, 78, 368-374.

Vygotsky, L. S. (1978). Mind in society. Cambridge, MA: Harvard University Press.

Weick, K. (1979). The social psychology of organizing (2nd ed.). Reading, MA: Addison-Wesley.

Wertsch, J. V. (1991). A sociocultural approach to socially shared cognition. In L. B. Resnick, J. M. Levine, \& S. D. Teasley (Eds.), Perspectives on socially shared cognition (pp. 85100). Washington, DC: American Psychological Association.

Wertsch, J. V., Del Rio, P., \& Alvarez, A. (Eds.). (1995). Sociocultural studies of mind. New York: Cambridge University Press. 